\title{
Bilateral superficial brachial artery
}

\section{Sharma $T^{1}$, Singla RK ${ }^{2}$, Sachdeva $K^{3}$}

${ }^{1}$ Professor and Head of Department, ${ }^{2}$ Associate Professor, ${ }^{3}$ Junior Resident, Department of Anatomy, Government Medical College, Amritsar, India

\begin{abstract}
Variations of the upper limb arterial system are well documented. Accurate knowledge of the normal and variant arterial anatomy of the axillary artery is important for clinical procedures and vascular radiology. In this article, a rare bilateral variation of superficial brachial artery is being reported. The axillary artery on both sides divided in its third part into a superficial brachial artery passing superficial to the lateral root of median nerve and brachial artery proper. The former terminated in the cubital fossa by dividing into ulnar and radial arteries while the later descended deep to the medial root of median nerve and gave anterior and posterior circumflex humeral branches of axillary artery and profunda brachii of brachial artery. Then it terminated by giving twigs to muscles of arm. Earlier superficial brachial artery is reported with a prevalence rate varying from $0.2-25 \%$ but a bilateral variation is extremely rare. Further its ontogeny and clinical implications are discussed in detail.
\end{abstract}

Key words: Superficial brachial artery, brachial artery, Axillary artery

$\mathrm{S}^{\mathrm{i}}$ ince variations in arterial pattern of upper limb are observed so frequently, it can be aptly said that variation is a rule rather than an exception. One such variation is superficial brachial artery in which the artery crosses superficial to median nerve. It is reported by different authors with a prevalence rate varying from $0.2-25 \%$. However almost all of them are silent about its bilateral occurrence. One such case was found in the Department of Anatomy, Government Medical College, Amritsar, Punjab, INDIA; where superficial brachial artery was found in both the upper limbs of a female cadaver.

\section{Case report}

During routine under graduate dissections on a 50 year female cadaver, it was observed that left axillary artery after giving subscapular artery in its third part bifurcated into two branches- superficial brachial artery and brachial artery proper. The former passed superficial to lateral root of median nerve and descended to the cubital fossa lying lateral to the median nerve in the arm. In the cubital fossa it bifurcated into radial and ulnar arteries. The brachial artery proper descended deep to the medial root of median nerve and gave anterior and posterior circumflex humeral branches of axillary artery and profunda brachii of brachial artery. Then it terminated by giving twigs to muscles of arm. (Fig 1)

A similar pattern of arteries was seen in the right arm also.

\section{Discussion}

A superficial brachial artery was first defined as the one which runs superficial to median nerve ${ }^{1}$. It may replace the main trunk or may be accompanied by an equally important, less important or more important trunk running deep to median nerve.

Table 1 depicts the prevalence of superficial brachial artery as observed by different authors from time to time. However none of them have commented upon its bilateral prevalence.

\section{Ontogeny}

Arey $(1957)^{9}$ is of the view that anomalous blood vessels may arise due to:

(i) The choice of unusual paths in primitive vascular plexus.

(ii) The persistence of vessels normally obliterated

(iii) The disappearance of vessels normally retained

(iv) Incomplete development

(v) Fusions and absorption of the parts usually distinct

Correspondence

Dr. Kanika Sachdeva

Chander Niwas, 61, Lawrence Road

Amritsar- 143001

Punjab, India

E-mail: kanikadr.sarang@yahoo.com 
Table 1: Prevalence of superficial brachial artery

\begin{tabular}{|c|l|c|c|}
\hline S. No. & Name of Author & Year & $\mathbf{\%}$ \\
\hline 1. & Quains2 & 1844 & 0.2 \\
\hline 2. & Miller3 & 1939 & 3.0 \\
\hline 3. & Mc Cormeck et al4 & 1953 & 5.75 \\
\hline 4. & Keen5 & 1961 & 12.3 \\
\hline 5. & Lippert \& Pabst6 & 1985 & 22.0 \\
\hline 6. & Baeza et al7 & 1995 & 11.9 \\
\hline 7. & Patnaik et al8 & 2002 & 6.0 \\
\hline
\end{tabular}

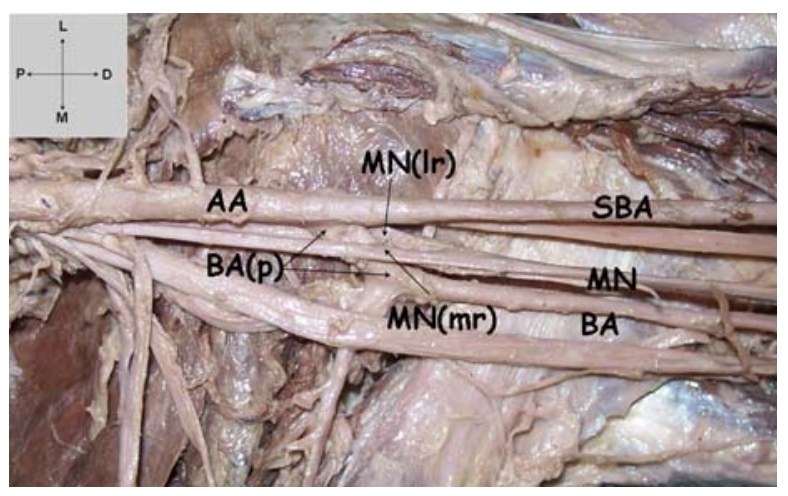

Fig 1: Left Axilla \& Arm

\section{Abbreviations}

AA- Axillary Artery,

SBA- Superficial Brachial Artery,

BA (p)- Brachial Artery Proper,

MN- Median Nerve,

$\mathrm{MN}(\mathrm{mr})-$ Median Nerve (medial root),

MN (lr)- Median Nerve (lateral root)

In the present case it seems that in Stage III of Singer ${ }^{10}$ ulnar artery came from brachial artery as usual. Superficial brachial artery continued as radial artery and anastomosis between superficial brachial artery and brachial artery developed normally. (See Fig 2-A)

However brachial artery between origin of superficial brachial artery and ulnar artery ('a' in Fig 2-B) retrogressed and severed its communication with common interosseous artery. The superficial brachial artery failed to retrogress and continued to supply radial artery. The anastomosis between superficial brachial artery and brachial artery ('b' in Fig 2-B) which usually forms proximal part of radial artery now formed proximal part of ulnar artery, thus giving appearance that ulnar artery and radial artery are terminal branches of superficial brachial artery and common interosseous artery ('c' in Fig 2-B) came as a branch of ulnar artery.

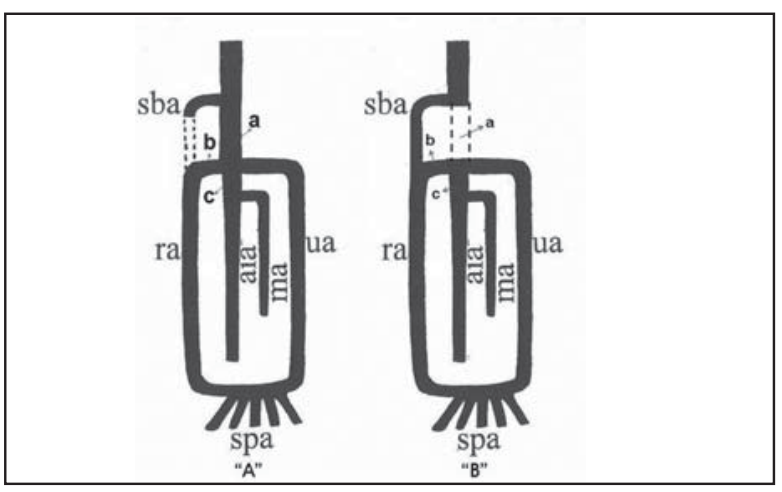

Fig 2: (A) - Normal Development of Human Brachial artery. (Singer, 1933)

(B) - Development as in the present case.

\author{
Abbreviations \\ sba: Superficial brachial artery \\ ra: Radial artery \\ ua: Ulnar artery \\ ma: Median Artery \\ aia: Anterior Interosseous Artery \\ spa: Superficial Palmer Arch
}

\section{Conclusion}

Superficial position of brachial artery not only makes it more vulnerable to trauma and thus to bleeding but also more accessible to cannulation if needed. It may be mistaken for a vein and if certain drugs are injected into it, the results may be disastrous like gangrene or loss of a hand ${ }^{8}$.

\section{References}

1. Adachi B. Arterensystem des japaner. Kyoto. 1928; 1: 205-10.

2. Quains. The Anatomy of Arteries of Human Body. London: Taylor \& Walton; 1844. 43-54.

3. Miller RA. Observations upon the arrangement of Axillary artery \& Brachial plexus. Am J of Anat. 1939; 64:143-63. 
4. Mc Cormack LJ, Cauldwell EW, Anson BJ. Brachial \& antebrachial arterial patterns. Surg Gynaecol Obst. 1953; 96: 43-54.

5. Keen JA. A study of arterial variations in the limbs with special reference to symmetry of vascular pattern. Am J of Anat. 1961;108: 24561.

6. Lippert H, Pabst R. Arterial Variations in Man. New York: Springer; 1985. 68-73.

7. Baeza RA, Nebot H, Ferreira B, Reina F, Perer J, Saundo JR et al. An anatomical study \& ontogenic explanation of 23 cases with variations in main pattern of brachio antebrachial arteries. Journal of Anatomy. 1995; 187(2): 473-9.

8. Patnaik VVG, Kalsey G, Singla RK. Branching Pattern of Brachial Artery- A Morphological Study. J Anat Soc Ind. 2002; 51(2):176-86.

9. Arey LB. Developmental Anatomy: Development of Arteries. 6th ed. Philadelphia: WB Saunders' Co: 1957.p. 375-7.

10. Singer E. Embryological patterns persisting in the arteries of the arm. Anat Rec. 1933; 55: 40613. 